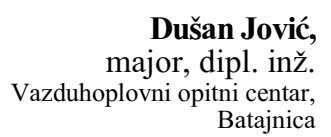

Batajnica

\section{ODREĐIVANJE PARAMETARA POUZDANOSTI GRUPE ELEKTRONSKIH UREĐAJA VAZDUHOPLOVA PRIMENOM GRAFIČKE METODE}

UDC: $621.38 .004 .15: 623.746]: 519.674$

Rezime:

Pouzdanost vazduhoplova, njegovih sistema i opreme jedan je od važnijih problema koji se mora razmotriti $i$ analizirati. Ovaj rad analizira podatke o otkazima grupe elektronskih uređaja na vazduhoplovu u periodu od nekoliko godina i opisuje proces odredivanja parametara pouzdanosti navedenih elektronskih uređaja korišćenjem grafičke metode.

Ključne reči: pouzdanost, parametri pouzdanosti, normalna raspodela, lognormalna raspodela, grafičke metode, papir verovatnoće, histogram.

\title{
DETERMINATION OF AVIONICS EQUIPMENT RELIABILITY PARAMETERS USING GRAPHIC METHODS
}

Summary:

Reliability of aircraft and their systems and equipment is one of the most important problems which must be considered and analysed. This analysis is based on the number and periods of failures for the last few years and it describes the determination of the parameters of aircraft avionics reliability using certain graphic methods.

Key words: reliability, reliability parameter, normal distribution, lognormal distribution, graphic methods, graph-paper, histogram.

\section{Uvod}

U suočavanju sa problemima koji se javljaju u održavanju složenih sistema poput vazduhoplova, od planiranja utroška i obnove resursa, obučavanja ljudstva, obezbeđenja odgovarajućeg alata i ispitno-merne opreme, sprovođenja propisane tehnologije održavanja [1] itd., kao zaseban izdvojio se problem pouzdanosti - pouzdanosti aviona kao celine, ali i njegovih sistema i uređaja.

U širem, praktičnom i teorijskom smislu, korene pouzdanosti kao naučne discipline treba tražiti u zahtevima koje su u prvoj polovini dvadesetog veka postavile vojske, tradicionalno najveći potrošači državnog budžeta, svojim dobavljačima i proizvođačima. Pomenuti zahtevi odnose se, pre svega, na rad oružjauređaja-sistema u što je moguće dužem periodu eksploatacije bez otkaza.

Dalji civilizacijski napredak omogućio je pojavu i široku primenu mnoštva uređaja koji su morali biti razmotreni kroz prizmu pouzdanosti, vodeći računa o ceni proizvoda koji je otkazao, značaju njegovog ispravnog rada i eventualnog 
redundovanja, proceni veličine stoka rezervnih delova i uređaja, troškovima skladištenja, transporta i slično.

Ono što umanjuje pouzdanost elemenata - sistema na vazduhoplovu jesu ekstremni uslovi rada (ekstremni za pojam statičnih, zemaljskih uređaja), kao što su: relativno brze promene temperature, pritiska i vlažnosti okoline, aerodinamičko (kinetičko) zagrevanje, velika opterećenja (od negativnih do pozitivnih g), udari, vibracije.

Navedeni uslovi upotrebe zahtevaju niz kompenzacionih mera radi umanjenja njihovog negativnog uticaja, što svakako višestruko uvećava ionako visoku cenu uređaja koji se ugrađuju u vazduhoplove. Takođe, intenzivno upošljavaju tehnomenadžere u pronalaženju odgovarajućeg balansa na terazijama ,potrebne tehničke karakteristike - cena uređaja“"

Određivanje (prognoza) pouzdanosti pojedinih uređaja može se izvršiti po MILL standardima (MIL HDBK), vodeći računa o uslovima, kao što je to urađeno za neke uređaje veze u $[2,3,4]$.

Model teorijske raspodele pojave otkaza primenjen je na uzorak koji čine sledeći radio-navigacioni uređaji:

- upravljačka kutija radio-stanice UK-100; DOR;

- primopredajnik radio-stanice $\mathrm{KON}$ -

- primopredajnik radio-stanice ER-4;

- radio-kompas VARK-01.

Određivanju pokazatelja pouzdanosti primenom grafičke metode pristupilo se na osnovu dostupnih statističkih podataka o otkazima navedenih uređaja, pri čemu se nije ulazilo u razloge (unutrašnje ili spoljne) otkaza.

\section{Metodologija proračuna}

Procedure do kojih se u istraživanju oblasti pouzdanosti došlo, pre svega, omogućuju odbacivanje određene raspodele kao neodgovarajuće. One nikada u potpunosti ne potvrđuju određenu raspodelu kao adekvatnog predstavnika modela otkaza.

Umanjenje neizvesnosti u donošenju odluke o prihvatanju modela u direktnoj je vezi sa brojem raspoloživih podataka. Naime, što je veći broj podataka veća je verovatnoća odbijanja neadekvatnog modela. To praktično znači da se postavlja hipoteza o tome da li uzorak dolazi iz specificirane raspodele (bilo da je ona kontinualna ili diskretna) i da tu hipotezu treba potvrditi ili odbaciti.

Metodologija određivanja parametara pouzdanosti [5] na osnovu empirijskih podataka svodi se na rešavanje tri zadatka:

- prikupljanje uzorka - statističkog materijala i postavljanje hipoteze o klasi funkcije raspodele kojoj pripada slučajna veličina na bazi posmatranja uzorka;

- proveru ispravnosti postavljene hipoteze;

- određivanje nepoznatih parametara raspodele i ocenu njihove tačnosti.

Metode koje se primenjuju za utvrđivanje raspodele kojom se mogu aproksimirati prikupljeni podaci globalno se mogu svrstati u dve glavne grupe:

- grafičke metode;

- analitičke metode.

Svaka od njih ima prednosti i nedostatke: analitičke su objektivnije ali i komplikovanije, grafičke su brze i relativno jednostavne, ali manje objektivne od analitičkih.

Grafičke metode su upravo zbog pomenute jednostavnosti često korišćene $u$ 
inženjerskoj praksi za pronalaženje klase funkcije raspodele i njenih parametara, $i$ aproksimiranje skupa određenih statističkih podataka. Međutim, baziranjem na vizuelnom ispitivanju uzorka bez ikakvih statističkih izračunavanja, raste subjektivni momenat u izboru modela, što predstavlja njihov glavni nedostatak.

Dve grafičke metode se jasno diferenciraju. Prva, u kojoj postoji mogućnost konstrukcije histograma ili funkcije kumulativne raspodele posmatranog statističkog materijala i druga, koja u osnovi ima ucrtavanje skupa statističkih podataka na tzv. papire verovatnoće.

Metodom konstrukcije histograma stvara se mogućnost upoređivanja sa funkcijom gustine pretpostavljene raspodele ili njenom kumulativnom funkcijom.

Ako se ispituje $n$ sistema počev od vremena $\mathrm{t}=0$, onda će $\mathrm{u}$ bilo kom trenut$\mathrm{ku}$ vremena $\mathrm{t}$ biti $\mathrm{n}_{1}$ sistema koji nisu otkazali. Ovaj metod može se razložiti na nekoliko koraka:

- uređenje skupa eksperimentalno (iskustveno) dobijenih podataka $\mathrm{u}$ vremenskom domenu po neopadajućem nizu;

- izračunavanje empirijske gustine otkaza $\mathrm{f}_{\mathrm{e}}(\mathrm{t})$ pomoću izraza:

$f_{e}(t)=\frac{\frac{n_{1}\left(t_{i}\right)-n_{1}\left(t_{i}+\Delta t_{i}\right)}{n}}{\Delta t_{i}}=\frac{n_{1}\left(t_{i}\right)-n_{1}\left(t_{i}+\Delta t_{i}\right)}{n \cdot \Delta t_{i}}$

gde je $\mathrm{t}_{\mathrm{i}}<\mathrm{t}<\mathrm{t}_{\mathrm{i}}+\Delta \mathrm{t}_{\mathrm{i}}$, tj. funkcija gustine jednaka je odnosu između broja otkaza $u$ intervalu $\Delta \mathrm{t}_{\mathrm{i}} \mathrm{i}$ ukupnog broja sistema $\mathrm{n}$, podeljeno dužinom intervala $\Delta t_{i}$.

- funkcija intenziteta otkaza brojčano je jednaka odnosu između broja otkaza u vremenskom intervalu i broja siste- ma koji nisu otkazali na početku tog intervala, podeljenog sa dužinom intervala:

$\lambda(t)=\frac{\frac{n_{1}\left(t_{i}\right)-n_{1}\left(t_{i}+\Delta t_{i}\right)}{n_{1}\left(t_{i}\right)}}{\Delta_{i}}=\frac{n_{1}\left(t_{i}\right)-n_{1}\left(t_{i}+\Delta t_{i}\right)}{n_{1}\left(t_{i}\right) \cdot \Delta t_{i}}(2)$

- određivanje širine intervala koji nije strogo specificiran i zavisi od konkretnog slučaja, ali se optimalni broj intervala $\mathrm{k}$ može izračunati po formuli:

$K=1+3,3 \log (n)$,

gde je n veličina uzorka;

- crtanje histograma tako što se na apscisu nanose vrednosti intervala nad kojima se crta pravougaonik, čija visina odgovara vrednosti funkcije. Ukupna površina ispod histograma jednaka je jedinici;

- upoređivanje oblika histograma sa graficima funkcije gustine raspodele karakterističnih raspodela;

- određivanje najboljeg modela.

Glavni nedostatak ovog postupka je nemogućnost razlikovanja uzroka greške, tj. da li je greška posledica teorijskog modeliranja ili fluktuacije skupa statističkih podataka. Takođe, u slučaju raspolaganja suviše malim uzorkom ovaj metod postaje nepouzdan, tako da je preporučljivo da se primenjuje na veće statističke uzorke.

Metoda određivanja funkcije raspodele verovatnoće primenom papira verovatnoće može se primeniti u slučaju određivanja funkcije raspodele sa jednim ili dva parametra. U slučaju da ima više parametara svodi se na slučaj dvoparametarske raspodele. Pri ucrtavanju podataka na papir verovatnoće treba se pridržavati sledećeg redosleda: 
- na osnovu skupa statističkih podataka pripremiti papir verovatnoće pretpostavljene raspodele;

- preurediti podatke u rastući niz izvršiti sortiranje niza u neopadajući;

- ucrtati na papir verovatnoće tačke sa koordinatama, tako da se vrednosti podataka nanose na apscisu, a vrednosti funkcije na ordinatu po sledećem:

[t(i), $(i / 0,5) / n]$

ako se verovatnoća daje u apsolutnim vrednostima,

ili kao $[t(i), 100(i / 0,5) / n]$

ako se verovatnoća daje u procentima (\%);

- povući pravu liniju kroz ovako dobijene tačke proizvoljno ili korišćenjem metode najmanjih kvadrata;

- proceniti gomilanje tačaka na pravoj ili oko nje - ako se tačke nalaze na pravoj ili oko nje odabrani model je korektan; ako su odstupanja sistematska model nije odgovarajući;

- sa papira verovatnoće moguće je proceniti parametre raspodele.

Može se zaključiti da je procena o tome koliko tačke slede pravu liniju subjektivna, što predstavlja nedostatak ovog metoda.

\section{Rezultati i analiza}

Do podataka o otkazima došlo se obradom podataka iz odgovarajuće vazduhoplovno-tehničke dokumentacije i evidencije. Kao neposredni izvor informacija korišćen je obrazac - tehnički nalaz neispravnosti vazduhoplovno-tehničkog materijalnog sredstva.
Teorijski model raspodele određen je na sledeći način:

- tabelarno je prikazan statistički uzorak za svaki uređaj;

- konstruisani su histogrami za svaki skup podataka;

- podaci su uneti na odgovarajući papir verovatnoće;

- prihvaćen je (odnosno odbijen) pretpostavljeni model raspodele;

- izvršeno je izračunavanje parametara.

Podaci o vremenima otkaza $t_{i}$, vrednosti empirijske funkcije raspodele $F\left(t_{i}\right)$, širine intervala $\Delta \mathrm{t}_{\mathrm{i}}(\mathrm{h}) \mathrm{i}$ vrednosti empirijske funkcije gustine otkaza $f_{e}(t)$ prikazani su u tabelama, a izračunavaju se na osnovu sledećih formula:

$F\left(t_{j}\right)=(i-0,5) / n$

$f_{e}(t)=n_{1} /\left(n \Delta t_{i}\right)$

gde je $n_{1}$ broj uređaja koji su otkazali $u$ posmatranom intervalu.

Histogrami i funkcije raspodele na papiru verovatnoće sa unetim podacima prikazani su na slikama 1 do 8 .

Uređaj 1: Upravljačka kutija radio-stanice $U K-100$

Tabela 1 Vrednosti empirijske funkcije raspodele

\begin{tabular}{|c|c|c|}
\hline $\mathrm{i}$ & $\mathrm{t}_{\mathrm{i}}[\mathrm{h}]$ & $\mathrm{F}\left(\mathrm{t}_{\mathrm{i}}\right)$ \\
\hline 1 & 420 & 0,07 \\
\hline 2 & 547 & 0,21 \\
\hline 3 & 585 & 0,36 \\
\hline 4 & 696 & 0,5 \\
\hline 5 & 710 & 0,64 \\
\hline 6 & 750 & 0,78 \\
\hline 7 & 771 & 0,92 \\
\hline
\end{tabular}


Tabela 2 trebnom opsegu) na kojem su uneti podaVrednosti empirijske funkcije gustine otkaza

\begin{tabular}{|c|c|c|}
\hline$\Delta \mathrm{t}_{\mathrm{i}}[\mathrm{h}]$ & $\mathrm{n}_{1}$ & $\mathrm{f}_{\mathrm{e}}(\mathrm{t}) \cdot 10^{-4}$ \\
\hline $0-150$ & 0 & 0 \\
\hline $150-300$ & 0 & 0 \\
\hline $300-450$ & 1 & 9,5 \\
\hline $450-600$ & 2 & 28,5 \\
\hline $600-750$ & 3 & 28,5 \\
\hline $750-900$ & 1 & 9,5 \\
\hline
\end{tabular}
ci o vremenima otkaza upravljačke kutije UK-100 (prikazan je samo deo papira verovatnoće zbog uštede na prostoru).

$\mathrm{Na}$ osnovu podataka sa slike 2 vrši se određivanje parametara raspodele na sledeći način:

- srednja vrednost $\mu$ određuje se ta-

Na slici 2 prikazan je deo papira verovatnoće za normalnu raspodelu (u po-

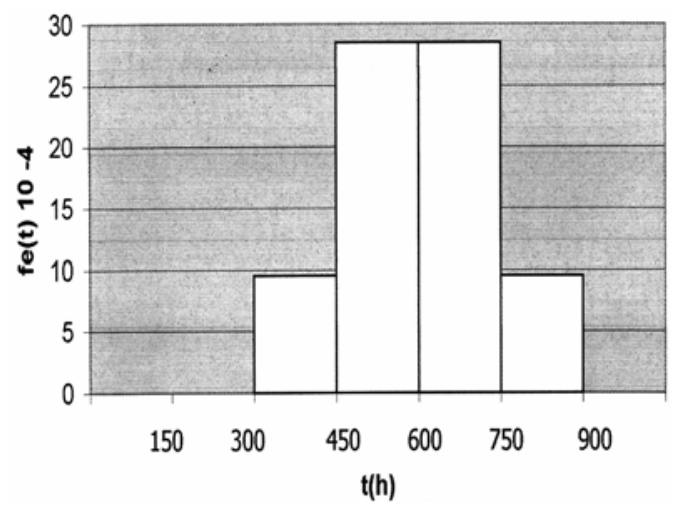

Sl. 1 - Histogram-funkcija kumulativne raspodele otkaza upravljačke kutije UK-100 ko što se na ordinati dijagrama nađe tačka 0,5 , povuče se horizontalna linija do preseka sa pravom i očita vrednost na apscisi $(\mu)$;

- standardna devijacija $\sigma \approx 2 \mathrm{D} / 5$, gde je D razlika između vrednosti na apscisi koje ogovaraju tačkama 0,9 i 0,1 na ordinati.

$\mathrm{Na}$ osnovu histograma i funkcije raspodele na papiru verovatnoće može se zaključiti da upravljačka kutija otkazuje po normalnom zakonu.

Dobijena funkcija gustine otkaza je:

$$
f(t)=\frac{1}{124 \cdot \sqrt{2 \pi}} e^{-\frac{1}{2}\left(\frac{t-680}{124}\right)^{2}}
$$

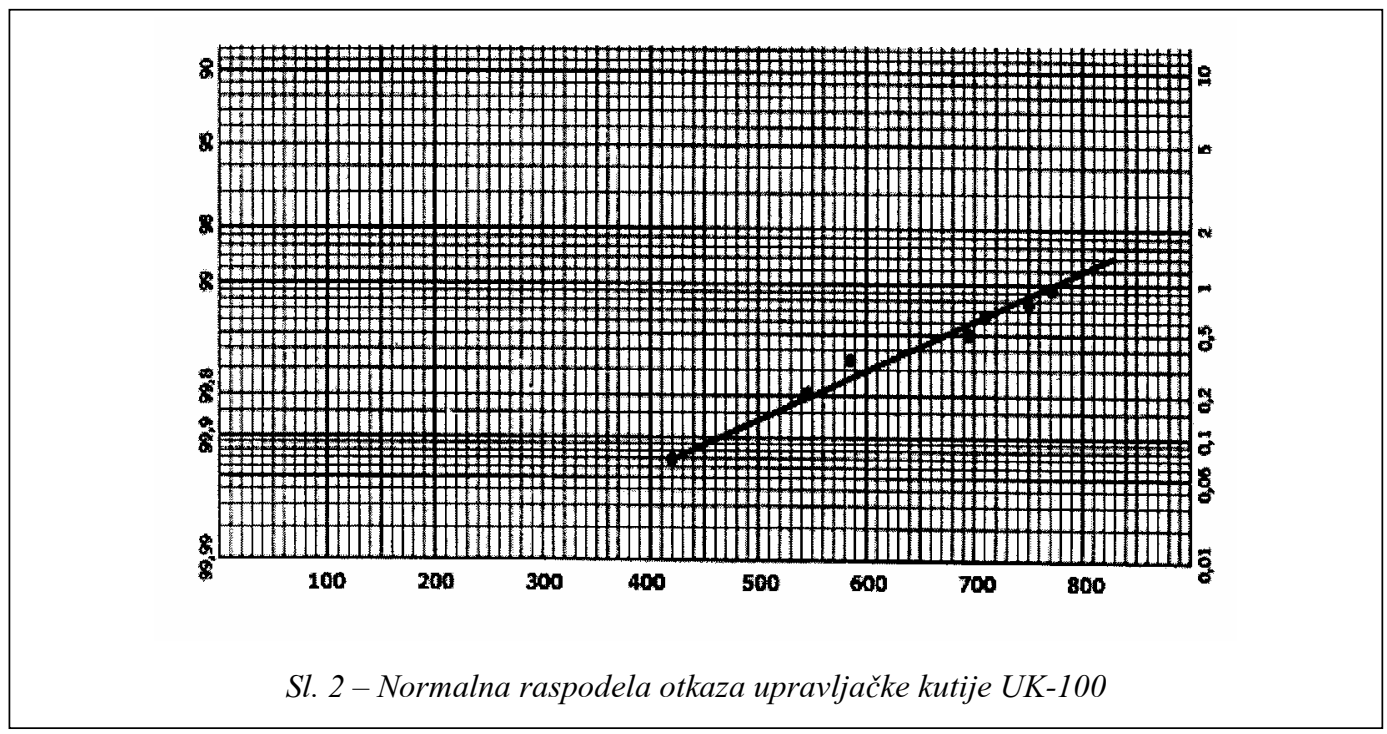


Uređaj 2: Primopredajnik radio-stanice KONDOR

Tabela 3 Vrednosti empirijske funkcije raspodele

\begin{tabular}{|c|c|c|}
\hline $\mathrm{i}$ & $\mathrm{t}_{\mathrm{i}}[\mathrm{h}]$ & $\mathrm{F}\left(\mathrm{t}_{\mathrm{i}}\right)$ \\
\hline 1 & 510 & 0,07 \\
\hline 2 & 608 & 0,21 \\
\hline 3 & 695 & 0,36 \\
\hline 4 & 814 & 0,5 \\
\hline 5 & 904 & 0,64 \\
\hline 6 & 948 & 0,78 \\
\hline 7 & 1013 & 0,92 \\
\hline
\end{tabular}

Tabela 4 Vrednosti empirijske funkcije gustine otkaza

\begin{tabular}{|c|c|c|}
\hline$\Delta \mathrm{t}_{\mathrm{i}}[\mathrm{h}]$ & $\mathrm{n}_{1}$ & $\mathrm{f}_{\mathrm{e}}(\mathrm{t}) \cdot 10^{-4}$ \\
\hline $0-200$ & 0 & 0 \\
\hline $200-400$ & 0 & 0 \\
\hline $400-600$ & 1 & 14,3 \\
\hline $600-800$ & 2 & 28,6 \\
\hline $800-1000$ & 3 & 42,9 \\
\hline $1000-1200$ & 1 & 14,3 \\
\hline
\end{tabular}

$\mathrm{Na}$ osnovu histograma i funkcije raspodele na papiru verovatnoće može se zaključiti da upravljačka kutija otkazuje po lognormalnom zakonu.

Dobijena funkcija gustine otkaza je:

$f(t)=\frac{1}{192 t \cdot \sqrt{2 \pi}} e^{-\frac{1}{2}\left(\frac{\ln t-840}{192}\right)^{2}}$

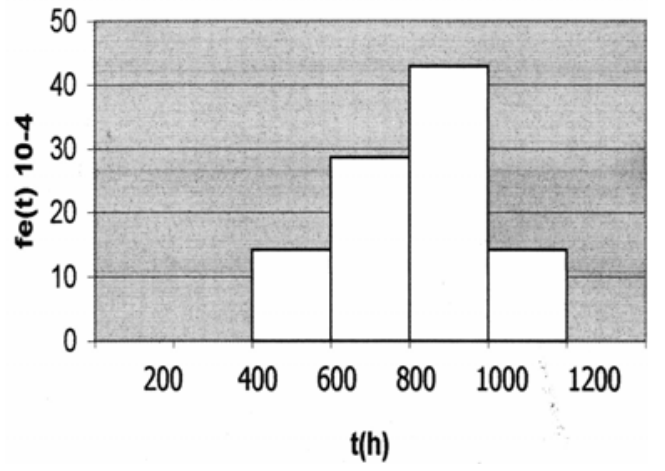

Sl. 3 - Histogram - funkcija kumulativne raspodele otkaza primopredajnika radio-stanice KONDOR

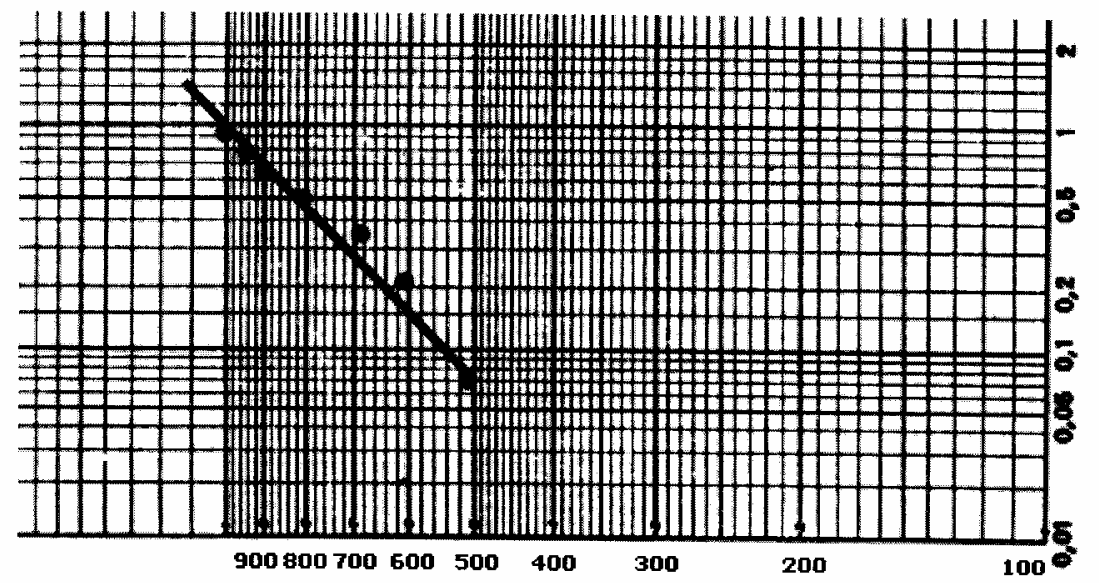

Sl. 4 - Lognormalna raspodela otkaza primopredajnika radio-stanice KONDOR 
Uređaj 3. Primopredajnik radio-stanice ER-4

Vrednosti empirijske funkcije raspodele

\begin{tabular}{|c|c|c|}
\hline $\mathrm{i}$ & $\mathrm{t}_{\mathrm{i}}[\mathrm{h}]$ & $\mathrm{F}\left(\mathrm{t}_{\mathrm{i}}\right)$ \\
\hline 1 & 24 & 0,0625 \\
\hline 2 & 64 & 0,1875 \\
\hline 3 & 86 & 0,3125 \\
\hline 4 & 123 & 0,4375 \\
\hline 5 & 140 & 0,5625 \\
\hline 6 & 143 & 0,6875 \\
\hline 7 & 156 & 0,8125 \\
\hline 8 & 194 & 0,9375 \\
\hline
\end{tabular}

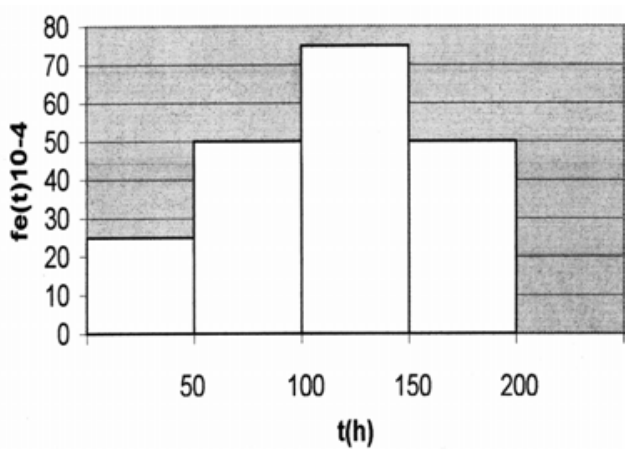

Sl. 5 - Histogram - funkcija kumulativne raspodele otkaza primopredajnika radio-stanice ER-4

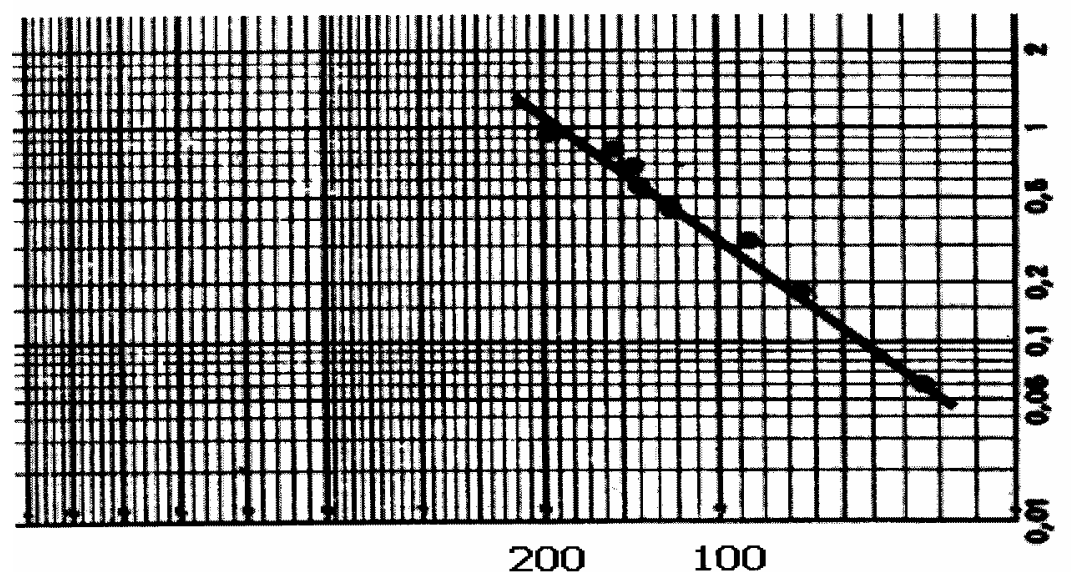

Sl. 6 - Lognormalna raspodela otkaza primopredajnika radio-stanice ER-4

Tabela 6

Vrednosti empirijske funkcije gustine otkaza

\begin{tabular}{|c|c|c|}
\hline$\Delta \mathrm{t}_{\mathrm{i}}[\mathrm{h}]$ & $\mathrm{n}_{1}$ & $\mathrm{f}_{\mathrm{e}}(\mathrm{t}) \cdot 10^{-4}$ \\
\hline $0-50$ & 1 & 25 \\
\hline $50-100$ & 2 & 50 \\
\hline $100-150$ & 3 & 75 \\
\hline $150-200$ & 2 & 50 \\
\hline
\end{tabular}

Funkcija gustine otkaza dobijena $\mathrm{u}$ ovom slučaju je:

$$
f(t)=\frac{1}{52 t \cdot \sqrt{2 \pi}} e^{-\frac{1}{2}\left(\frac{\ln t-125}{52}\right)^{2}}
$$

Uređaj 4. Prijemnik radio-kompasa VARK-01

Tabela 7

Vrednosti empirijske funkcije raspodele

\begin{tabular}{|c|c|c|}
\hline $\mathrm{i}$ & $\mathrm{t}_{\mathrm{i}}[\mathrm{h}]$ & $\mathrm{F}\left(\mathrm{t}_{\mathrm{i}}\right)$ \\
\hline 1 & 219 & 0,0625 \\
\hline 2 & 414 & 0,1875 \\
\hline 3 & 505 & 0,3125 \\
\hline 4 & 578 & 0,4375 \\
\hline 5 & 782 & 0,5625 \\
\hline 6 & 840 & 0,6875 \\
\hline 7 & 918 & 0,8125 \\
\hline 8 & 920 & 0,9375 \\
\hline
\end{tabular}


Tabela 8

Vrednosti empirijske funkcije gustine otkaza

\begin{tabular}{|c|c|c|}
\hline$\Delta \mathrm{t}_{\mathrm{i}}[\mathrm{h}]$ & $\mathrm{n}_{1}$ & $\mathrm{f}_{\mathrm{e}}(\mathrm{t}) \cdot 10^{-4}$ \\
\hline $0-200$ & 0 & 0 \\
\hline $200-400$ & 1 & 6,25 \\
\hline $400-600$ & 3 & 18,75 \\
\hline $600-800$ & 1 & 6,25 \\
\hline $800-1000$ & 3 & 18,75 \\
\hline
\end{tabular}

Dobijena funkcija gustine otkaza u ovom slučaju je:

$$
f(t)=\frac{1}{120 \cdot \sqrt{2 \pi}} e^{-\frac{1}{2}\left(\frac{t-740}{120}\right)^{2}}
$$

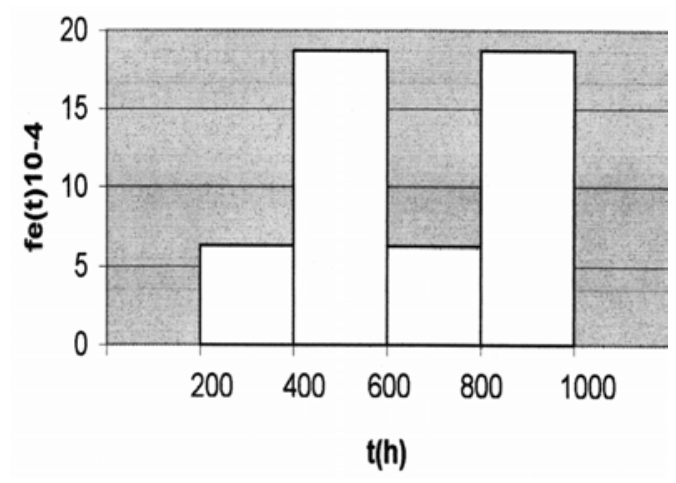

Sl. 7 - Histogram - funkcija kumulativne raspodele otkaza radio-kompasa VARK-01

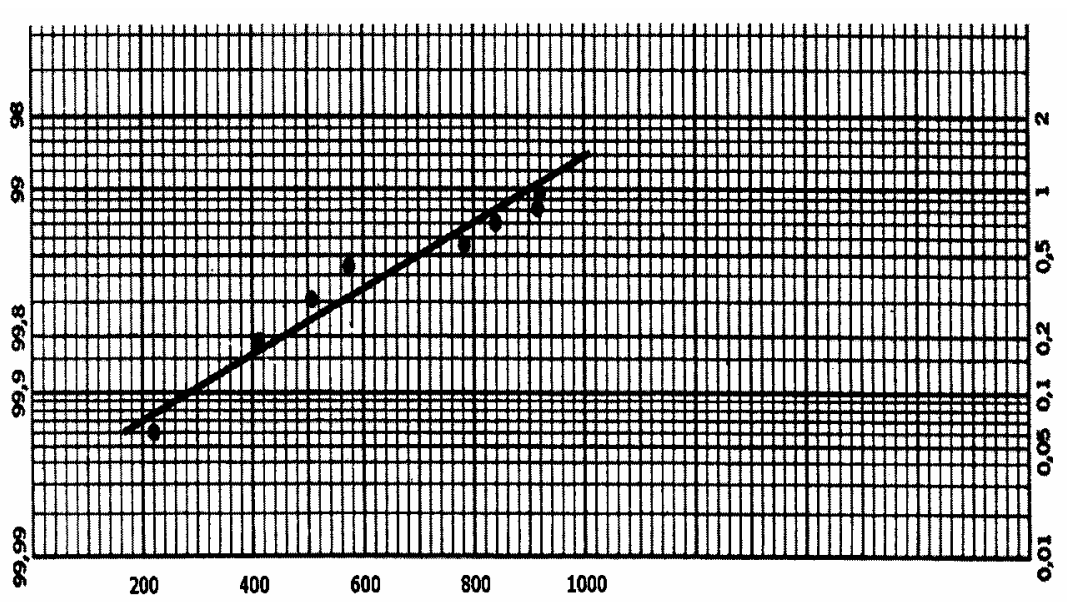

Sl. 8 - Lognormalna raspodela otkaza radio-kompasa VARK-01

\section{Zaključak}

Analiza otkaza grupe elektronskih uređaja vazduhoplova, prikazana u ovom radu, ostvarena je primenom grafičke metode. Metoda je i u ovom slučaju potvrdila svoje prednosti: praktičnost, brzinu i vizuelnost.

Kao statistički uzorak iskorišćeni su otkazi elektronskih uređaja različite namene: navigacionih i uređaja sredstava veze. Posmatran je period od nekoliko godina i na osnovu obrade podataka relativno skromnog uzorka došlo se do sledećeg zaključka: od analiziranih četiri dva uređaja otkazuju po normalnom, a dva po lognormalnom zakonu. To je u izvesnom neskladu sa teorijski prihvaćenim eksponencijalnim modelom kao reprezentom otkaza elektronskih uređaja. Ovo odstupanje javlja se zbog sledećih razloga [6]:

- uzorkovani uređaji nisu statični, već su ugradnjom na avione bili izloženi 
uticaju ekstremnih uslova različitih obli$\mathrm{ka}$ ispoljavanja $\mathrm{u}$ različitim vremenima $\mathrm{i}$ režimima rada: do otkaza je dolazilo u letu, pri sletanju, ali i na zemlji; nastajali su kao posledica udara, vibracija, velikih temperaturnih razlika, visoke vlažnosti; radili su kada i njihov nosač (često i češće) pod različitim opterećenjima (broj avio-poletanja u različitim periodima veka upotrebe svakog aviona nije bio isti). Kao što je u uvodu izloženo, raznovrsnost i priroda otkaza nije bila predmet ovog rada, već je za slučajnu promenljivu korišćeno samo vreme rada do otkaza uređaja;

- vreme rada do otkaza posmatrano je na uređajima koji su starili tokom upotrebe, dolazilo je do njihovog istrošenja, kada dominaciju preuzima normalna raspodela, odnosno lognormalna, ako je uzrok otkaza zamor materijala;
- mala veličina uzorka takođe je razlog mogućeg odstupanja od teorijske eksponencijalne raspodele.

$\mathrm{Na}$ osnovu dobijenih zakona raspodele može se planirati preventivno održavanje i optimizirati logistička podrška za analizirane uređaje [7].

Literatura:

[1] VTU SSNO, Upravljanje avionom N-62, VTUP, 1988.

[2] Parčina, N.; Ramović, R.: Modelovanje pouzdanosti magistrala za prenos podataka elektronskih sistema vazduhoplova u specijalnim uslovima eksploatacije, Zbornik radova SYM-OP-IS, str. 453-456, 1988.

[3] Parčina, N.; Ramović, R.: Reliability simulation of aircraft data transfer main lines, Prace Instituty Lotnicwa, str. 163-172, 1996.

[4] Milivojević, J.; Dragić, N.; Ramović, R.: Optimizacija pouzdanosti primopredajne radiostanice „KONDOR“, Zbornik radova SYM-OP-IS, str. 317-320, 2000.

[5] Vujanović, N.: Teorija pouzdanosti tehničkih sistema, VINC, Beograd, 1990.

[6] Jović, D.; Ramović, R.: Određivanje parametara pouzdanosti avionskih uređaja veze primenom grafičke metode, Zbornik radova TELFOR 2003, rad 5.3, Beograd, novembar 2003.

[7] Muždeka, S.: Logistika, logističko inženjerstvo, Institut za nuklearne nauke „Boris Kidrič“, Vinča, TU SSNO, 1981. 